\title{
QUAL LIBERDADE RELIGIOSA É BOA PARA OS NEGÓCIOS?
}

Aldir Guedes Soriano

Universidade do Oeste Paulista - UNOESTE. Curso de Direito, Presidente Prudente - SP. E-mail: aldirsoriano@me.com

\section{RESUMO}

Segundo o estudo do pesquisador norte-americano Brian Grim, a analise estatística de dados coletados ao redor do mundo permite afirmar que a liberdade religiosa é boa para a economia e também para os negócios. A partir desse dato objetivo, o presente trabalho demonstra que somente a liberdade religiosa fundada no liberalismo político pode ser realmente benéfica tanto para a sociedade quanto para a economia, e também para os negócios. Além disso, o trabalho apresenta duas concepções jus-filosófica que fundamental a liberdade pública em estudo: 1) liberal, já mencionada e 2) Anti-liberal.

Palavras-chaves: Liberdade religiosa. Negócios. Democracia. Liberalismo.

\section{WHICH RELIGIOUS FREEDOM IS GOOD FOR BUSINESS?}

\begin{abstract}
According to Brian Grim's research, the statistical analysis of data collected around the world allows us to say that religious freedom is good for the economy and also for business. This article shows that only the religious freedom founded on political liberalism can be really beneficial both to society and to the economy, and also for business. In addition, this article presents two jusphilosophical religious freedom concepts: 1) liberal, already mentioned and 2) Illiberal (antiliberal).
\end{abstract}

Keywords: Religious Freedom. Businesses. Democracy. Liberalism. 
INTRODUÇÃO

Estudos recentemente divulgados pelo presidente da Religious Freedom \& Business Foundation, Brian J. Grim, comprovam que não apenas a liberdade religiosa é boa para os negócios, mas que, além disso, a ausência dessa liberdade prejudica a atividade empresarial. Essa relevantíssima e impactante constatação soa, hoje, como novidade aos ouvidos de empresários e até mesmo dos estudiosos das ciências sociais e jurídicas. Economistas do século dezessete, todavia, já haviam chegado às mesmas conclusões. Assim, Hery Parker mostra em seu livro of a free trade, publicado no ano de 1648 , que a liberdade religiosa é condição para a prosperidade comercial. Para Willian Petty, a intolerância é um obstáculo aos negócios e também ao enriquecimento das nações. Segundo Petty, o cultivo da liberdade religiosa neste contexto contribui para o desenvolvimento de um mundo mais pacífico e tolerante. De fato, essa evidente realidade ficou esquecida por séculos.

\section{FUNDAMENTOS DA LIBERDADE RELIGIOSA}

Liberdade religiosa, entretanto, não é expressão de significado único. Resgatar os fundamentos jurídicos é imprescindível para se saber qual liberdade religiosa é boa para os negócios. Há duas correntes conflitantes que fundamentam esse direito, conforme o artigo Liberal Democracy and the Right to Religious Freedom, publicado recentemente na revisita Law Review da Universidade norte americana Brigham Young. (SORIANO, 2013, p. 2 e ss.) Em síntese, a primeira corrente, amparada pelo pensamento liberal de John Locke, fundamenta a liberdade religiosa no direito de escolha: autonomia da consciência individual. A segunda corrente, idealizada por John Garvey, pode ser denominada antiliberal ou simplesmente não liberal e fundamenta a liberdade religiosa na premissa de que a religião é uma coisa boa. A corrente liberal é mais favorável e democrática. Por outro lado, esse estudo aponta para os riscos, caso o Estado adotasse a corrente antiliberal. Nesse caso, o Estado teria que definir o que é Religião e, consequentemente, o que restringiria a liberdade de todos aqueles que não se enquadrassem nesse conceito religioso. Em outras palavras, o Estado adotaria o consenso religioso coletivo pré-definido, em detrimento da autonomia da consciência religiosa individual. Somente haveria liberdade dentro desses estreitos limites. Essa corrente da liberdade religiosa é antiliberal na medida em que destrói um dos elementos estruturante do liberalismo: autonomia individual.

Assim sendo, a liberdade religiosa - alicerçada no pensamento liberal da autonomia da consciência individual e consagrada nas constituições dos países democráticos e, também, nos tratados de direitos humanos - é boa para os negócios. 
É evidente que a liberdade religiosa - alicerçada no antiliberalismo não pode ser boa para os indivíduos, nem para a coletividade e nem, muito menos, para os negócios. Essa liberdade religiosa é cerceadora da liberdade religiosa e potencialmente geradora de tensões, hostilidades, perseguições e, até mesmo, violências religiosas. Com essa carga negativa, não é viável o desenvolvimento de ambientes de trabalho que sejam produtivos.

O fundamento antiliberal da liberdade religiosa pode ser associado ao estabelecimento de uma única igreja oficial. Das treze colônias americanas, nove apresentavam igrejas estabelecidas, ou seja, unidas ao Estado. A colônia de Rhode Island, fundada por Roger Williams, era uma das exceções, pois não tinha igreja unida ao Estado e, por conseguinte, permitia plena liberdade religiosa. Por isso, a colônia de Rhode Island representava a proteção para inúmeros colonos que eram perseguidos, principalmente por guardarem o sábado e não o domingo.

A Declaração de Direitos de Virginia de 1776 foi o primeiro documento liberal a estabelecer a idéia da universalidade dos direitos naturais ou inatos. A mesma ideia foi posteriormente reproduzida na Declaração de Independência dos Estados Unidos de 1776, na Declaração Francesa dos Direitos do Homem e do Cidadão de 1789, e até mesmo na Declaração Universal dos Direitos Humanos de 1948. Assim sendo, o mundo ocidental adotou o liberalismo como fundamento de todos os direitos fundamentais incluindo o direito à liberdade religiosa.

\section{BINÔMIO RELIGIÃO \& LIBERDADE}

Não há dúvidas de que a liberdade religiosa - alicerçada no pensamento liberal - é boa para os negócios. Mas o que dizer da religião? É a religião benéfica para os negócios?

Há evidências históricas no sentido de que a religião pode ser boa para os negócios desde que esteja, acima de tudo, associada à liberdade. Por outro lado, aliada à tirania e à opressão, a religião pode fomentar a perseguição e a violência. Nessas condições, os negócios não prosperam, pois não encontram o substrato necessário para o seu desenvolvimento. Daí o resultado: estagnação econômica. Durante o século XX, a associação entre ateísmo e poder político resultou em danos ainda maiores. O totalitarismo ateu e marxista foi responsável pelos maiores genocídios registrados na historia da humanidade. O resultado foi catastrófico: ruína econômica, fome e a morte de milhões de pessoas, a exemplo do que aconteceu na União Soviética e na China. 0 cientista político Rummel estima que mais de 98 milhões de pessoas foram mortas por regimes marxistas no século passado. (RUMMEL, 1994, p. 8) É verdade que muito sangue foi derramado em nome de Deus ou através de guerras religiosas. Entretanto é forçoso concluir que o ateísmo comunista foi muito mais deletério e assassino. 
A liberdade religiosa diminui a possibilidade de opressão tanto da religião quanto do ateísmo. Isso não significa que a religião e o ateísmo são necessariamente inimigos da liberdade. A tirania e a opressão decorrem, geralmente, da aliança com o poder político. Assim, a liberdade religiosa contribui significativamente para a pacificação da sociedade ao reduzir as tensões existentes na sociedade.

Até mesmo ideias boas e aparentemente inofensivas podem ser utilizadas com intensões maléficas. Nesse sentido, Thomas Sowell demostra em seu livro Os intelectuais e a Sociedade, como as ideias pacifistas divulgadas na Europa facilitaram a invasão de nações praticamente desarmadas como a França e a Inglaterra pelo poderoso exercito nazista de Hitler. Enquanto a Alemanha estava se armando até os dentes, outras nações eram militarmente enfraquecidas mediante o discurso pacifista dos chamados "intelectuais ungidos". Se isso pode acontecer com o uso de expressões benevolentes como "pacifismo", o que não pode ser realizado em nome da religião, da igualdade, dos direitos humanos, da democracia e até mesmo da liberdade religiosa, sobretudo, por personalidades motivadas pelo desejo incontrolável de dominar, libido dominandi, e com uso do artifício da novilíngua, em que o significado original dos vocábulos são pervertidos, como antevê a literatura orweliana? É, "todos são iguais, mas alguns são mais iguais que os outros".

\section{LIBERDADE RELIGIOSA É BOA PARA AS NAÇÕES}

Não há dúvidas de que os Estados Unidos se tornaram a nação mais próspera do globo com o fundamento deste binômio: Religião e Liberdade. Ao visitar os Estados Unidos, no século XIX, o que mais chamou a atenção do historiador francês Alexis de Tocqueville foi a influência religiosa cristã na prosperidade econômica dessa jovem nação democrática. (HOLMES, 2006, pp. 1-31) A moral cristã foi o principal fundamento estruturante da democracia liberal norte-americana, baseada na livre iniciativa e na liberdade de consciência e de crença. Esse legado foi exportado para todo o mundo ocidental, mediante migração do liberalismo constitucional.

O cristianismo, segundo o historiador BENJAMIN F. MORRIS, foi importante para o estabelecimento das instituições democráticas norte-americanas. Ainda segundo BENJAMIN F. MORRIS:

"Cristianismo é o principal e mais influente elemento, mais profundo e mais sólido fundamento, de todas as nossas instituições civis. É a religião do povo - a religião nacional, mas não tivemos nem o estabelecimento da Igreja nem o estabelecimento da religião. Um estabelecimento da Igreja implica a conexão entre a Igreja e o Estado, e o controle do poder civil e político pelo poder eclesiástico e espiritual assim como o controle destes poderes pelos anteriores. 
(...) “Os fundadores da República cristã da América do Norte adotaram o símbolo da liberdade civil e religiosa como a grande ideia e fim de todas as instituições civis." (MORRIS, 2007, pp. 39-54)

É importante ressaltar que o binômio Religião \& Liberdade encontrou terreno fértil nos Estados Unidos, em razão da positiva influência do pensamento liberal, uma vez que não houve o estabelecimento de nenhuma igreja oficial. Isso foi fundamental para o desenvolvimento das instituições democráticas e, por conseguinte, para a prosperidade econômica da nação americana.

\section{CONTRASTE ENTRE A LUZ E AS TREVAS}

A Foto noturna da região asiática realizada recentemente, a partir da Estação Espacial Internacional (ISS), mostra que a Coréia do Norte está nas trevas em virtude do baixo desenvolvimento urbano e econômico. A nação norte-coreana é um exemplo de como a falta de liberdade é deletéria para os negócios. Sob o regime comunista, as liberdades fundamentais não são asseguradas ao povo. Vítimas da perseguição religiosa e política são encarceradas em campos de concentração com trabalhos forçados.

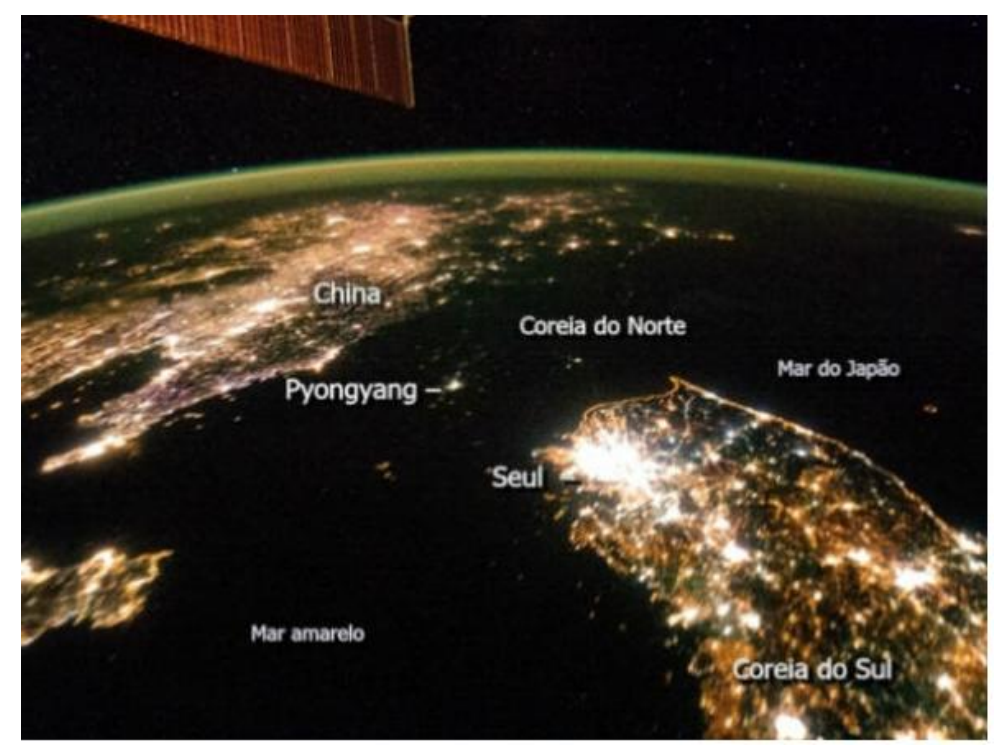

\section{Figura 1.}

Fonte: http://exame.abril.com.br/tecnologia/noticias/coreia-do-norte-desaparece-em-foto-noturna-feita-do-espaco

O contraste com a Coréia do Sul é evidente. O liberalismo e a liberdade econômica permitiram o desenvolvimento econômico e social.

$\mathrm{Na}$ foto, a China aparece luminosa contrastando com a escuridão da Coréia do Norte. Nesse país, a liberdade religiosa, embora garantida constitucionalmente, é cerceada através do 
controle do Partido Comunista Chinês - PCCh. Algumas religiões são perseguidas e seus seguidores, por vezes, são enviados a campos de concentração, denominados por campos de reeducação. Então, a falta de liberdade na China não foi obstáculo para o seu desenvolvimento econômico? Aparentemente não, porque o governo chinês associou a tirania comunista ao livre mercado. Assim, o livre mercado permitiu o desenvolvimento econômico, mas sobretudo, com maciços investimentos dos Estados Unidos, sem os quais a China estaria tão apagada quanto à Coréia do Norte. Além disso, é razoável admitir que a falta de liberdades, incluindo tanto a liberdade de expressão quanto de religião, atue impactando negativamente o desenvolvimento econômico e social.

O desenvolvimento econômico do modelo chinês juntou a tirania totalitária com o livre mercado. Disso resultou algum desenvolvimento econômico, mas os campos de concentração na China pouco diferem dos campos de concentração da Coréia do Norte. Melhor resultado econômico, social e humano seria alcançado se a China tivesse adotado a democracia liberal com todas as liberdades públicas e não apenas em parte a liberdade econômica.

\section{LIBERDADE RELIGIOSA É BOA PARA OS NEGÓCIOS}

Há dois motivos por que o direito à liberdade religiosa deve ser respeitado no universo corporativo. Primeiro, porque se trata de direito assegurado pela Constituição Federal e, segundo, porque é benéfica para os negócios. O primeiro motivo é jurídico, o segundo é econômico.

Ocorre que o direito fundamental à liberdade religiosa, assegurado constitucionalmente apresenta eficácia nas relações privadas. Os direitos humanos, em grande medida, representam prerrogativas da pessoa humana em relação ao Estado. Em outras palavras, os direitos humanos limitam o poder estatal e permitem as liberdades individuais, o que significa dizer que o Estado não pode violar direitos fundamentais, como a vida, a liberdade e a igualdade. Ocorre, porém, que os direitos humanos fundamentais também possuem eficácia nas relações privadas. Tal eficácia já foi muito discutida na Alemanha, nas décadas de 50 e 60 . No Brasil, não resta nenhuma dúvida acerca da eficácia dos direitos humanos entre particulares. No RE no 201.819-8-RJ (Rel. Min. Ellen Gracie), o ministro do STF, Gilmar Mendes, proferiu voto propugnando pela eficácia privada dos direitos fundamentais.

A novidade de que a liberdade religiosa - alicerçada na autonomia da consciência individual - é boa para os negócios representa motivação extra para que as empresas assegurem de fato os direitos fundamentais de seus empregados. Há, portanto, uma segunda razão, agora de ordem econômica, para que as empresas respeitem o direito à liberdade religiosa de seus 
empregados. Ao assim proceder, as empresas são beneficiadas. Elas se tornam mais eficientes e lucrativas.

Conflitos e tensões relacionados com a religião podem estar presentes no ambiente coorporativo, como a guarda de um dia de descanso religioso, - sábado ou domingo. A liberdade é a solução para esses conflitos e tensões. Como nos disse o Presidente da Religious Freedom \& Business Foundation, Brian J. Grim, em entrevista publicada na revista Consulex № 408 - 15 de Janeiro/2014, "a liberdade religiosa permite transformar o que poderia ser motivo de divisão em união de forças".

\section{CONSIDERAÇÕES FINAIS}

É importante relembrar que a liberdade religiosa está inter-relacionada com as demais liberdades, incluindo a liberdade de expressão e, também, a liberdade econômica. As liberdades humanas são universais, indivisíveis, interdependentes e inter-relacionadas, conforme a Declaração de Viena de 1993.

A liberdade religiosa, aliada às demais liberdades públicas e fundamentada na autonomia da consciência individual, contribui indubitavelmente para a pacificação da sociedade. Isso é bom para a nação. No ambiente corporativo também pode gerar bem-estar. É evidente que o ambiente amistoso favorece o aumento da produtividade, garantido às empresas um aumento dos rendimentos financeiros.

A liberdade religiosa pode, portanto, fazer uma nação grande e livre; e uma empresa mais humana e lucrativa.

\section{REFERÊNCIAS}

GARVEY, John. What are freedoms for? Cambridge: Harvard University Press, 2000.

GRIM, Brian J. and FINKE, Roger. The Price of Freedom Denied: Religious Persecution and Conflict in the Twenty-First Century. New York: Cambridge University Press, 2010. http://dx.doi.org/10.1017/CB09780511762345

HOLMES, David L. The faiths of the founding fathers. New York: Oxford University Press, 2006, pp. $1-31$.

MORRIS, Benjamin F. The Christian Life and Character of the Civil Institutions of the United States, 2007.

RUMMEL, R. J. Death by Government. New Brunswick: Transaction Publishers, 1994. 
SORIANO, Aldir Guedes. Liberal Democracy and the Right to Religious Freedom, 2013 BYU L. Rev. 581 (2014). Disponível em: http://digitalcommons.law.byu.edu/lawreview/vol2013/iss3/8. 